\title{
Hypogonadotropic hypogonadism associated with another small supernumerary marker chromosome (sSMC) derived from chromosome 22, a case report
}

\author{
Abdullah ${ }^{1 \#}$, Cui Li ${ }^{2 \#}$, Minggang Zhao ${ }^{2}$, Xiang Wang ${ }^{2}, \mathrm{Xu} \mathrm{Li}^{2}$, Junping Xing ${ }^{1}$ \\ ${ }^{1}$ Department of Urology, The First Affiliated Hospital of Xi'an Jiaotong University, Xi'an, China; ${ }^{2}$ Centre for Translational Medicine, The First \\ Affiliated Hospital of Xi'an Jiaotong University, Xi'an, China \\ \#These authors contributed equally to this work. \\ Correspondence to: Junping Xing. Department of Urology, School of Medicine, The First Affiliated Hospital, Xi'an Jiaotong University, Xi'an 710061, \\ China. Email: xingjpsx@sina.cn.
}

\begin{abstract}
The idiopathic hypogonadotropic hypogonadism (IHH) is portrayed as missing or fragmented pubescence, cryptorchidism, small penis, and infertility. Clinically it is characterized by the low level of sex steroids and gonadotropins, normal radiographic findings of the hypothalamic-pituitary areas, and normal baseline and reserve testing of the rest of the hypothalamic-pituitary axes. Delay puberty and infertility result from an abnormal pattern of episodic GnRH secretion. Mutation in a wide range of genes can clarify $\sim 40 \%$ of the reasons for $\mathrm{IHH}$, with the majority remaining hereditarily uncharacterized. New and innovative molecular tools enhance our understanding of the molecular controls underlying pubertal development. In this report, we aim to present a 26-year-old male of IHH associated with a small supernumerary marker chromosome (sSMC) that originated from chromosome 22. The G-banding analysis revealed a karyotype of 47,XY,+mar. High-throughput DNA sequencing identified an 8.54 Mb duplication of 22q11.1-q11.23 encompassing all the region of $22 \mathrm{q} 11$ duplication syndrome. Pedigree analysis showed that his mother has carried a balanced reciprocal translocation between Chromosomes 22 and $\mathrm{X}[\mathrm{t}(\mathrm{X} ; 22)]$. To the best of our knowledge, this is the second confirmed case of IHH with an sSMC deriving from chromosome 22. Based on our study, the duplicated chromosome fragment 22q11.1-q11.23 might be the reason for the phenotype of our case. Meanwhile, High-throughput DNA sequencing combined with cytogenetic analysis can provide a more accurate clinical diagnosis for patients carrying sSMCs.
\end{abstract}

Keywords: Small supernumerary marker chromosome (sSMC); 22q11.1-q11.23; 22q11 duplication syndrome; high-throughput DNA sequencing; hypogonadotropic hypogonadism $(\mathrm{HH})$

Submitted Jul 12, 2020. Accepted for publication Feb 22, 2021.

doi: $10.21037 /$ tau-20-1087

View this article at: http://dx.doi.org/10.21037/tau-20-1087

\section{Introduction}

Idiopathic hypogonadotropic hypogonadism (IHH) is a rare genetic disease, which is described by missing or inadequate puberty, cryptorchidism, infertility, and small penis in males. It is mainly because of deficiency in the secretion or function of gonadotropin-releasing hormone $(\mathrm{GnRH})(1,2)$. Until now, around 50 genes have been reported to be associated with $\mathrm{IHH}$, which account for only $50 \%$ of IHH cases (2). Small supernumerary marker chromosomes (sSMC) are little, extra, and abnormal chromosomes, which are present along with the other 46 normal chromosomes. It is usually equivalent in size to or a little smaller than chromosome 20 of a similar metaphase spread, and can't be portrayed by regular banding cytogenetics (3). The frequency of sSMC is $0.044 \%$ in newborn, $0.075 \%$ in prenatal cases, $0.288 \%$ in mentally retarded patients and $0.125 \%$ in subfertile subjects (4). Some studies believed that $6-19 \%$ of sSMCs are originated from chromosome $22(5,6)$. About $80 \%$ of sSMCs 
originated from chromosome 22 are presented as nonmosaic dicentric duplications of $22 \mathrm{q} 11.2$, and congenital abnormalities like malignant tumors, and the cat-eye syndrome were associated with clinical phenotypes (7).

However, marker chromosomes are very rare in $\mathrm{IHH}$ cases. Up to now, it has been reported that only 1 infertile male case of hypogonadotropic hypogonadism (HH) carried chromosome aberrations of a supernumerary inv dup22q11.1 (8). In this report, we present the first case of a supernumerary dup22q11.1-q11.23 with IHH. The current case had a karyotype of $47, \mathrm{XY},+\mathrm{mar}$, and was assessed for delayed puberty. We present the following article in accordance with the CARE reporting checklist (available at http://dx.doi.org/10.21037/tau-20-1087).

\section{Case presentation}

A 26-year-old male patient presented in our department was examined properly and then referred for chromosome analysis because of genital retardation with cryptorchidism. He was born as a second child of a healthy Chinese couple. He also suffered from congenital heart disease, cataract, and retinal detachment, but no smell disorders. The medical history of the patient was unremarkable, with no significant history of hazard factors, drugs, toxins, or radiation. Physical examination: height $165 \mathrm{~cm}$, body proportion is normal. No development of bilateral breasts. The penis is juvenile with sparse pubic hair. No testes are touched in bilateral dysplastic scrotum. While testes can be touched in the bilateral inguinal region, and the volume of testes was $3 \mathrm{ml}$, respectively. Repeated hormone analysis (chemiluminescence method) indicated $\mathrm{HH}$, with a lower level of serum testosterone $(0.214-1.302 \mathrm{nmol} / \mathrm{L}$, normal range is $8.64-29.0 \mathrm{nmol} / \mathrm{L}$ ), relatively low folliclestimulating hormone level $(2.263-3.2 \mathrm{mIU} / \mathrm{mL}$, normal range is $1.5-12.4 \mathrm{mIU} / \mathrm{mL}$ ) and normal luteinizing hormone level $(1.484-1.68 \mathrm{mIU} / \mathrm{mL}$, normal range is $1.7-$ $8.6 \mathrm{mIU} / \mathrm{mL})$.

The other sex hormones were normal, estradiol (12.029$40.1 \mathrm{pmol} / \mathrm{L}$, normal range is $28-156 \mathrm{pmol} / \mathrm{L}$ ), progesterone $(0.314-0.75 \mathrm{nmol} / \mathrm{L}$, normal range is $0.159-0.5 \mathrm{nmol} / \mathrm{L})$, prolactin $(9.4-9.62 \mathrm{ng} / \mathrm{mL}$, normal range is $4.04-15.2 \mathrm{ng} / \mathrm{mL}$ ), dehydroepiandrosterone sulfate $(5.59 \mathrm{umol} / \mathrm{L}$, normal range is $4.34-12.2 \mu \mathrm{mol} / \mathrm{L}$ ). Thyroid function tests (chemiluminescence assay) showed normal with serum triiodothyronine [T3 $6.54 \mu \mathrm{g} / \mathrm{dL}$, normal range is $4.4-$ $13.5 \mu \mathrm{g} / \mathrm{dL}$ ], thyroxine [T4 $1.61 \mathrm{ng} / \mathrm{mL}$, normal range is
$0.78-2.20 \mathrm{ng} / \mathrm{mL}$ ] and thyroid-stimulating hormone [TSH $0.98 \mathrm{uIU} / \mathrm{mL}$, normal range is $0.25-5 \mathrm{uIU} / \mathrm{mL}$ ]. Bone age assessment based on hand $\mathrm{X}$-ray Image showed as boys aged 15-16. All procedures performed in studies involving human participants were in accordance with the ethical standards of the institutional and/or national research committee(s) and with the Helsinki Declaration (as revised in 2013). Written informed consent was obtained from the patient.

\section{Cytogenetics}

After obtaining written informed consent, approved by the Human Research Ethics board of the First Affiliated Hospital, School of medicines, Xi'an Jiaotong University, chromosomal analysis was carried out on peripheral blood lymphocytes (PBL) cultures using GTG banding technique based on 300-400 band level according to the standard protocol. The parents' karyotypes of the proposita(proband) with $47, \mathrm{XY},+$ mar was further examined to analyze the source and presence of additional small marker chromosomes.

\section{Molecular cytogenetics (detection of chromosome aberration)}

Chromosome aberration, i.e., Chromosomal aneuploidy or a known pathogenic genomic copy number variation (CNVs) above $100 \mathrm{~Kb}$ of PBL were tested by Highthroughput DNA sequencing, i.e., Next-generation sequencing technology.

\section{Results}

\section{Chromosome G-banding analysis of patients}

The chromosomal analysis confirmed sSMCs in blood lymphocytes, in all metaphases $(n=200)$, each containing an additional marker chromosome, i.e., G-banding karyotype of chromosome 47,XY,+mar (Figure 1).

\section{Detection results of chromosome aberration}

High-throughput DNA sequencing of the proband revealed a result of: seq[hg19]dup22q11.1-q11.23, chr22:g.16840001_25380000dup, which is an $8.54 \mathrm{Mb}$ region of the chromosome 22 q11.1-q11.23 repeats (Figure 2), including all of the $22 \mathrm{q} 11$ duplication syndrome (Appendix 1). 


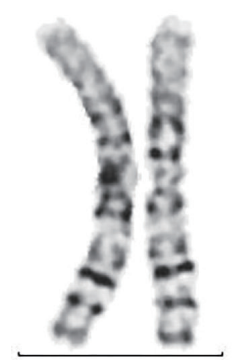

1

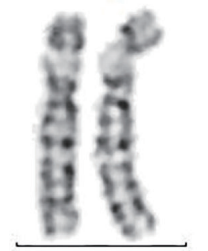

6

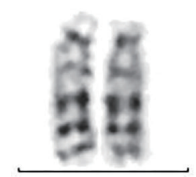

13

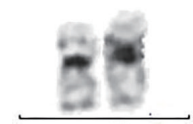

19

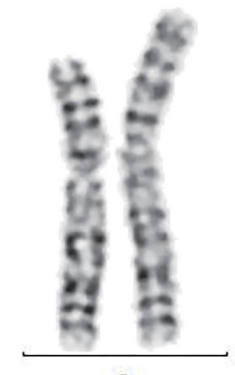

2

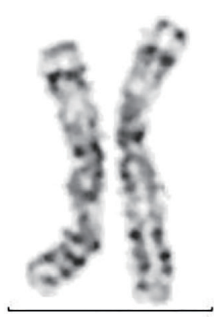

3

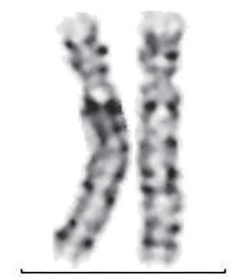

4

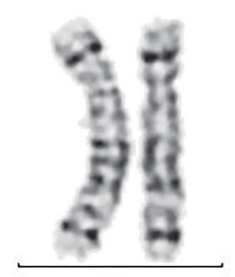

5

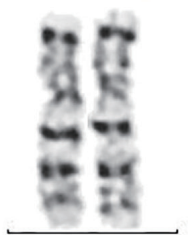

7

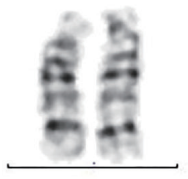

14

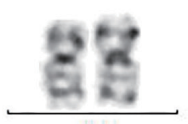

20

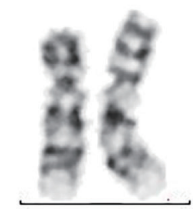

9

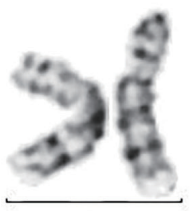

8

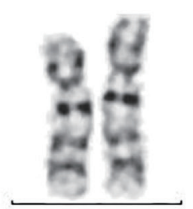

10

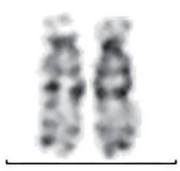

15

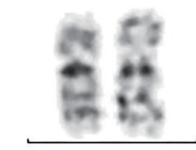

16

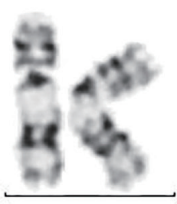

11

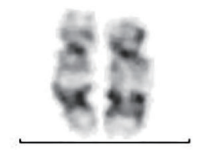

17

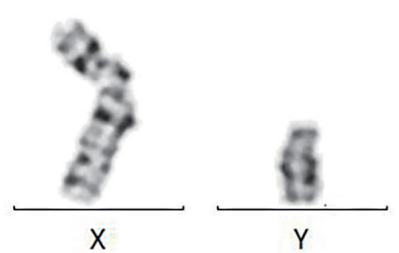

Figure 1 Metaphase karyotype of the patient in GTG banding displaying the detected small supernumerary marker chromosomes: $47, \mathrm{XY},+\mathrm{mar}$.

\section{Pedigree investigation and genetic study of the proband}

The paternal karyotypes were normal, and the maternal chromosome banding revealed a balanced reciprocal translocation between chromosome 22 and $\mathrm{X}$ chromosome, which is 46, $\mathrm{X}, \mathrm{t}(\mathrm{X} ; 22)$ (p22.3; q11.2) (Figure 3). Therefore, it is suggested that the genetic abnormality in the patient with supernumerary dup22q11.1-q11.23 was inherited from his mother.

\section{Discussion}

The small supernumerary chromosome markers (sSMC) are defined by Liehr et al., whereas abnormal chromosome structure cannot be identified just by using conventional cytogenetic techniques. They have the same size or are smaller than the metaphase chromosome 20 in the same preparation. A larger event on Ssmc found in some databases showed that they may be present in a karyotype with an abnormal number (e.g., down's syndrome), or with abnormal structure (e.g., balanced translocation, and ring chromosomes). It is believed that most of the sSMC found in normal healthy people come from the short arm of the acrocentric chromosomes. Euchromatin-free sSMCs are usually not harmful. However, duplications near 22q centromere are clinically insignificant (4). The published data presented sSMCs, a supernumerary inv dup22q11.1 in infertile men with $\mathrm{HH}$ (9). However, in various studies on sterile males, sSMCs were found more often than expected. An incidence of $0.3 \%$ was found in men from the oligozoospermic group and $0.2 \%$, in men of the IVF and ICSI groups (9).

In 2011, Mikelsaar et al. (8) introduced the first case of $\mathrm{HH}$ with a marker chromosome. The patient was 32 years 


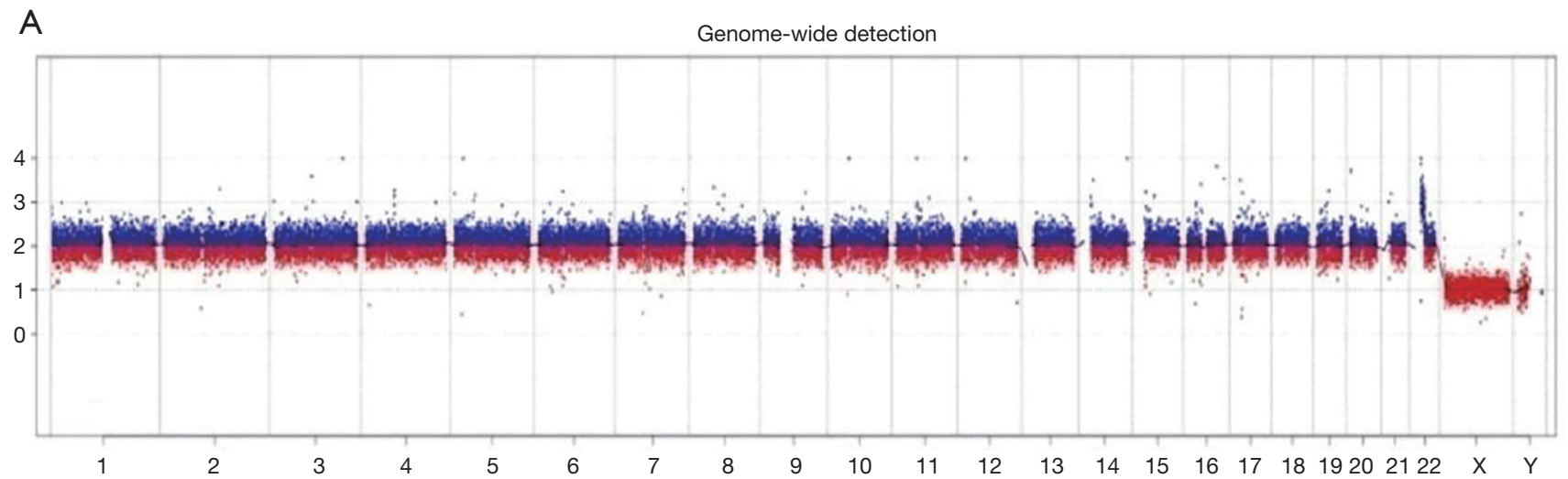

B

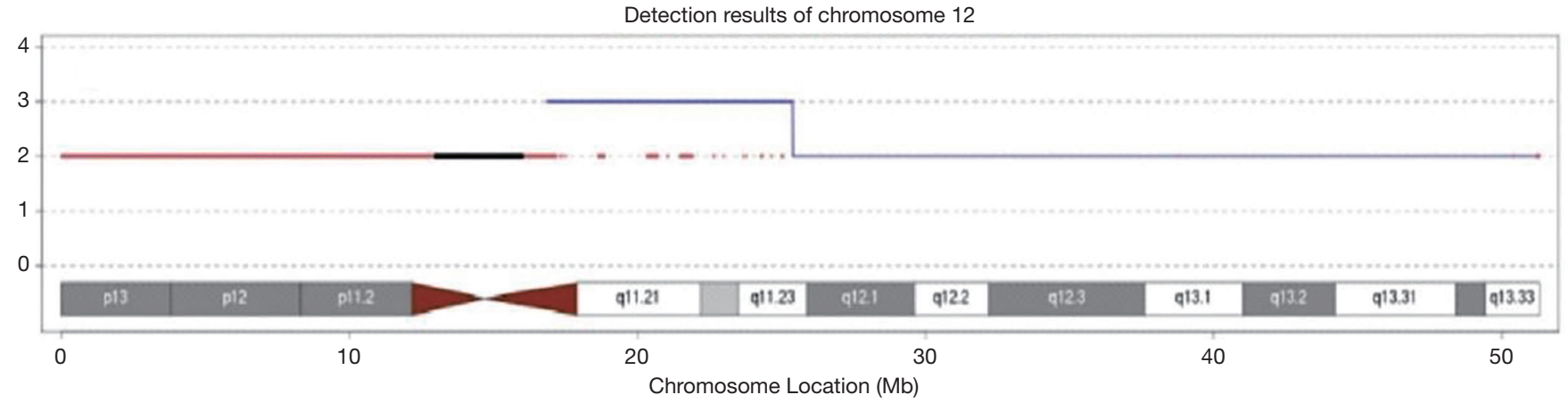

Figure 2 Result of chromosomal aneuploidy or a known pathogenic genomic copy number variation (CNVs) above $100 \mathrm{~Kb}$ : (A) genomewide detection showed Genome copy number variation (CNVs) increased, originating from chromosome 22; (B) detection of chromosome 22 showed a $8.54 \mathrm{Mb}$ Trisomy duplication in the $22 \mathrm{q} 11.1-\mathrm{q} 11.23$ region.

of age with a 47,XY,+mar karyotype, presented with growth and developmental delay, microphallus, and bilateral cryptorchidism. The marker originating from chromosome 22 was determined (distance $~ 9.6-14.4 \mathrm{Mb}$ from 22 pter to $22 \mathrm{q} 11.1$ ) utilizing the fluorescent in situ hybridization (FISH) technique.

In our case, the karyotype of the G-band chromosome analysis revealed sSMCs in blood lymphocytes i.e., $47, \mathrm{XY},+$ mar. Detection of Genome-wide by nextgeneration sequencing technology showed an $8.54 \mathrm{Mb}$ duplication in the chromosome $22 \mathrm{q} 11.1-\mathrm{q} 11.23$ region, including all of the 22q11 duplication syndrome. Pedigree investigation and genetic study of the proband suggested the genetic abnormality in the patient with supernumerary dup22q11.1-q11.23 was inherited from the mother, who has a balanced reciprocal translocation between Chromosome 22 and X Chromosome, 46,X,t(X;22)(p22.3;q11.2). 22q11 duplication syndrome has an incomplete appearance, and the patient's phenotype varied from normal, almost normal to multiple defects, mild learning difficulties, and shared features with DiGeorge/velocardiofacial syndromes (DGS/VCFS), including heart defects, velopharyngeal insufficiency with or without cleft palate, or hypernasal speech, and urogenital abnormalities $(10,11)$. Our patient who carried a sSMC also had retarded puberty, bilateral cryptorchidism, and microphallus as a primary symptom, which coincides with the literature data that the acrocentric sSMC has a causative role in male $\mathrm{HH}$, and its presence is more frequently associated with oligozoospermia (7\%) and less with azoospermia $(<1 \%)(12)$.

The mechanism by which sSMC causes problems with $\mathrm{HH}$ in men is still unclear. As with other chromosomal abnormalities, supernumerary dup22q11.1-q11.23 can cause hypothalamic or pituitary dysfunction (13), which may induce impaired secretion of $\mathrm{GnRH}$. Molecular bases of $\mathrm{HH}$ are only recognized in $25-30 \%$ of patients, and mutations mainly occur in KAL1 (Xp22.32), FGFR1 (8p11.2-p11.1), and $G n R H R(4 \mathrm{q} 21.2)$ genes. These mutations adversely 


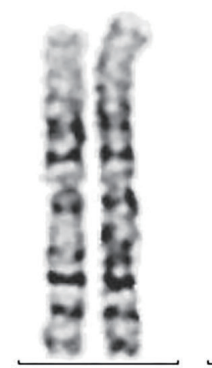

1

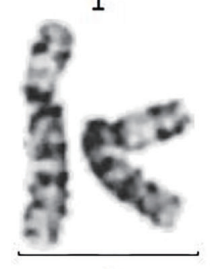

6

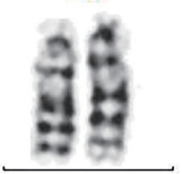

13

19

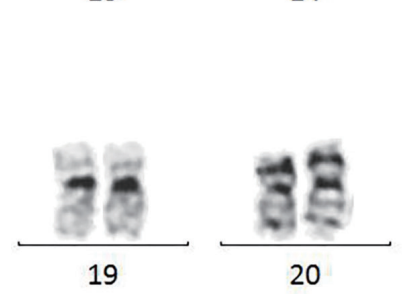

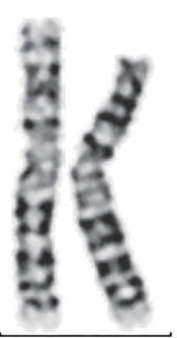

2

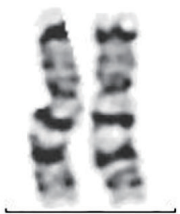

7

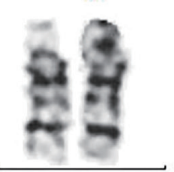

14

20

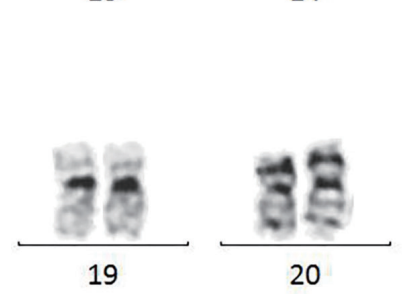

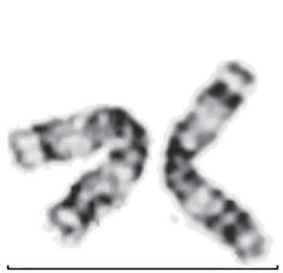

3

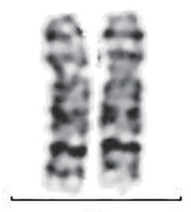

8

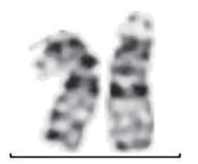

15

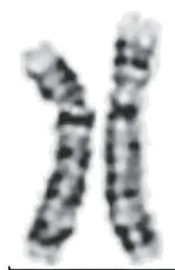

4

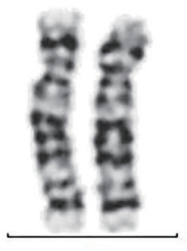

5

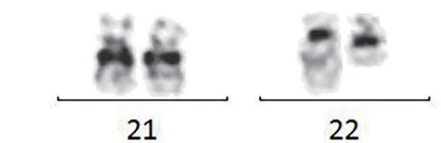

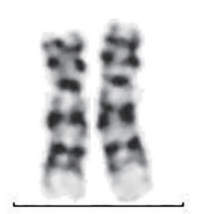

9

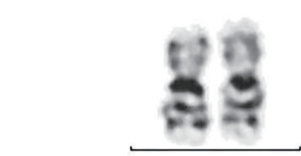

16

10
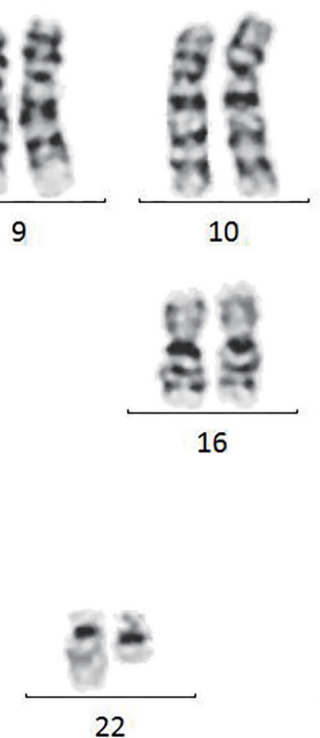

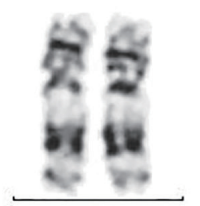

11

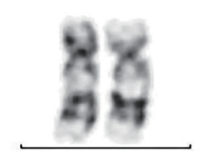

17

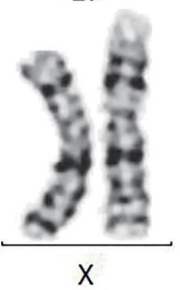

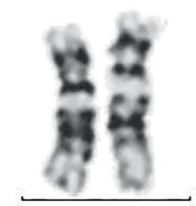

12

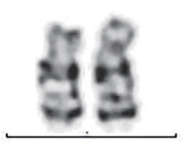

18

Figure 3 Metaphase karyotype of the patient's mother in GTG banding displaying balanced reciprocal translocation between Chromosome 22 and X Chromosome (arrow), i.e., 46,X,t(X;22)(p22.3; q11.2).

regulate neuroendocrine function and thus affect pubertal development, infertility, and spermatogenesis. Even though there are a large number of $\mathrm{HH}$ genes, none are located on chromosome 22. In our sample, it was found that no relevant molecular alterations had a possible connection with the phenotype by High-throughput DNA sequencing.

This patient had $\mathrm{HH}$ and carried supernumerary dup22q11.1-q11.23 causing trisomy of the centromeric and/or pericentromeric locale of chromosome 22. These regions are known to contain a series of highly repetitive DNA blocks, including genes that encode ribosomal structural RNA.

As far as we know, our case is the second case of $\mathrm{HH}$ with a sSMC originated from chromosome 22. By combining the information from the literature of Mikelsaar et al. (8), our results demonstrated that supernumerary dup22q11.1q11.23 might result in $\mathrm{HH}$ through disturbing GnRH secretion.
We suggest that the duplicated chromosome segment 22q11.1-q11.23 might be liable for the phenotype of our case and may likewise be an applicant locus of HH. Besides, he also suffered from congenital heart disease, cataracts, and retinal detachment. So, we suggest that each new case of IHH should simultaneously have some cytogenetics and molecular genetics tests, especially with multiple malformations. High-throughput DNA sequencing combined with cytogenetic analysis will give us more details about the accurate genotype-phenotype relationships for dysmorphic syndromes.

\section{Acknowledgments}

The authors thank the patient and his family.

Funding: This study was supported and funded by the Natural Science Basic Research program of Shaanxi 
province (Program No. 2020JQ-533).

\section{Footnote}

Reporting Checklist: The authors have completed the CARE reporting checklist. Available at http://dx.doi.org/10.21037/ tau-20-1087

Conflicts of Interest: All authors have completed the ICMJE uniform disclosure form (available at http://dx.doi. org/10.21037/tau-20-1087). The authors have no conflicts of interest to declare.

Ethical Statement: The authors are accountable for all aspects of the work in ensuring that questions related to the accuracy or integrity of any part of the work are appropriately investigated and resolved. All procedures performed in studies involving human participants were in accordance with the ethical standards of the institutional and/or national research committee(s) and with the Helsinki Declaration (as revised in 2013). Written informed consent was obtained from the patient.

Open Access Statement: This is an Open Access article distributed in accordance with the Creative Commons Attribution-NonCommercial-NoDerivs 4.0 International License (CC BY-NC-ND 4.0), which permits the noncommercial replication and distribution of the article with the strict proviso that no changes or edits are made and the original work is properly cited (including links to both the formal publication through the relevant DOI and the license). See: https://creativecommons.org/licenses/by-nc-nd/4.0/.

\section{References}

1. Karges B, Roux N. Molecular genetics of isolated hypogonadotropic hypogonadism and Kallmann syndrome. Endocr Dev 2005;8:67-80.

2. Stamou MI, Georgopoulos NA. Kallmann syndrome:

Cite this article as: Abdullah, Li C, Zhao M, Wang X, Li $\mathrm{X}$, Xing J. Hypogonadotropic hypogonadism associated with another small supernumerary marker chromosome (sSMC) derived from chromosome 22, a case report. Transl Androl Urol 2021;10(4):1797-1802. doi: 10.21037/tau-20-1087 phenotype and genotype of hypogonadotropic hypogonadism. Metabolism 2018;86:124-34.

3. Liehr T, Claussen U, Starke H. Small supernumerary marker chromosomes (sSMC) in humans. Cytogenet Genome Res 2004;107:55-67.

4. Liehr T, Weise A. Frequency of small supernumerary marker chromosomes in prenatal, newborn, developmentally retarded and infertility diagnostics. Int J Mol Med 2007;19:719-31.

5. Liehr T. Familial small supernumerary marker chromosomes are predominantly inherited via the maternal line. Genet Med 2006;8:459-62.

6. Viersbach R, Engels H, Gamerdinger U, et al. Delineation of supernumerary marker chromosomes in 38 patients. Am J Med Genet 1998;76:351-8.

7. Crolla JA, Youings SA, Ennis S, et al. Supernumerary marker chromosomes in man: parental origin, mosaicism and maternal age revisited. Eur J Hum Genet 2005;13:154-60.

8. Mikelsaar R, Lissitsina J, Bartsch O. Small supernumerary marker chromosome (sSMC) derived from chromosome 22 in an infertile man with hypogonadotropic hypogonadism. J Appl Genet 2011;52:331-4.

9. Mau-Holzmann UA. Somatic chromosomal abnormalities in infertile men and women. Cytogenet Genome Res 2005;111:317-36.

10. Ensenauer RE, Adeyinka A, Flynn HC, et al. Microduplication 22q11.2, an emerging syndrome: clinical, cytogenetic, and molecular analysis of thirteen patients. Am J Hum Genet 2003;73:1027-40.

11. Portnoï MF. Microduplication 22q11.2: a new chromosomal syndrome. Eur J Med Genet 2009;52:88-93.

12. Wang $\mathrm{W}, \mathrm{Hu} \mathrm{Y}, \mathrm{Zhu} \mathrm{H}$, et al. A case of an infertile male with a small supernumerary marker chromosome negative for M-FISH and containing only heterochromatin. J Assist Reprod Genet 2009;26:291-5.

13. Kim HG, Bhagavath B, Layman LC. Clinical manifestations of impaired GnRH neuron development and function. Neurosignals 2008;16:165-82. 


\section{Appendix:}

seq[hg19]dup(22)(q11.1q11.23)

chr22:g.16840001_25380000dup

RefSeqGenes:CRKL,THAP7,TPTEP1,ADORA2A,TUBA8,TUBA3FP,SNRPD3,TMEM191A,A

NKRD62P1-

PARP4P3,MIR648,CES5AP1,TMEM191B,TBX1,GSTT2,SUSD2,GNB1L,FBXW4P1,ARVCF, USP18,MIR3198-

1,POM121L4P,COMT,TANGO2,DGCR6L,MICAL3,P2RX6P,MIR301B,POM121L10P,ADOR A2A-

AS1,DGCR6,LINC00896,PI4KAP1,GAB4,IGLL1,DERL3,UFD1L,LOC101929374,ZNF280A, C22orf39,ZNF70,MIR130B,MIR5571,VPREB1,SNAP29,CLDN5,TXNRD2,PRODH,DGCR11, MED15,TMEM211,TSSK2,GSTT2B,C22orf29,MRPL40,LOC101928891,LOC100996342,SDF 2L1,RTN4R,LOC388849,RSPH14,MIR185,FAM230B,MIR3618,RGL4,SLC25A18,PI4KAP2, GUCD1,UBE2L3,CCT8L2,C22orf15,TMEM191C,THAP7-

AS1,TOP3B,BCRP2,ZNF74,GNAZ,FLJ41941,POM121L9P,HIC2,MIF,SLC25A1,DDT,CDC45,P IWIL3,HSFY1P1,BCR,BCL2L13,CLTCL1,GSTT1,SLC2A11,DGCR5,ATP6V1E1,BID,DGCR 2,DDTL,PEX26,HIRA,SPECC1L,CCDC116,DRICH1,RIMBP3B,TOP1P2,P2RX6,IGLL5,SGS M1,DGCR9,LOC391322,LRRC75B,DGCR14,PRAME,PI4KA,GSTTP2,LL22NC0363E9.3,POM121L1P,MAPK1,VPREB3,GP1BB,RIMBP3,GSTTP1,GUSBP11,LOC101929372, TRMT2A,MIF-AS1,YDJC,GGTLC2,LOC388882,LOC284865,MIR649,CECR6,SEPT5GP1BB,LINC01311,XKR3,SERPIND1,CHCHD10,GGT1,SLC7A4,RANBP1,CECR1,KLHL22, SMARCB1,LINC00895,LRRC74B,BMS1P20,BCRP3,MIR6816,SPECC1LADORA2A,AIFM3,CECR3,ZDHHC8,RAB36,LZTR1,GGT3P,POM121L8P,RIMBP3C,MIR65 0,ZDHHC8P1,ZNF280B,SCARF2,YPEL1,CABIN1,PPIL2,SEPT5,DGCR8,CECR2,CECR7,CE CR5,DGCR10,CECR5-

AS1,MIR1286,LINC00528,GGT5,MIR4761,PPM1F,GSC2,IL17RA,MIR1306,MMP11,UPB1. 